\title{
Adverse Cardiac Events Among the Patients Using Hydroxychloroquine and Azithromycin in COVID-19
}

\author{
Ibrahim Etem Dural ${ }^{1}$ (D), Yasemin Nadir² (iD \\ 1 Department of Cardiology, Afyonkarahisar University of Health Sciences, Afyonkarahisar, Turkey \\ 2 Department of Infectious Diseases and Clinical Microbiology, Afyon Sandıklı State Hospital, Afyonkarahisar, Turkey
}

\begin{abstract}
Background: Hydroxychloroquine (HQN) and azithromycin (AZ) were used in the treatment of coronavirus disease 2019 (Covid-19), which might lead to cardiac side effects.

Aim: We aimed to describe the safety of HQN and HQN+AZ in terms of cardiac events.

Materials and methods: The QTc intervals were calculated by examining the ecg records of the first day and fifth day of hospitalization the patients who received HQN with or without concominant AZ for treatment of Covid 19.

Results: We included 93 patients.Moderate QTc prolongation was detected in 3 (7.5\%) of 40 patients who received hydroxychloroquine monotherapy for five days. Critical qtc prolongation was not detected in any patient. Three $(5.6 \%)$ of 53 patients who received dual treatments had moderate QTc prolongation and two patients had critical qtc prolongation. Torsades de pointes was not detected among the patients.

Conclusion: Close ECG monitoring is necessary, and the frequency of ECG monitorization should be individualized in patients receiving azithromycin with hydroxychloroquine.

Keywords: Qtc prolongation, COVID-19, hydroxychloroquine, azithromycin
\end{abstract}

\section{INTRODUCTION}

1

he first case of COVID-19 was reported on 10 March 2020 in Turkey (1). Various treatment options have been used in all countries because of the lack of proven reatment (2). Among these options, hydroxychloroquine (HQN) and azithromycin (AZ) combination is expected to treat the disease (3). These two drugs have been used among the patients with moderate levelslevel of disease in many countries since the first day of the diagnosis of symptomatic disease.

HQN is used to treat autoimmune diseases and malaria; AZ is used in the treatment of various infections $(4,5)$. When used in their indications, the common side effect is QTc prolongation in electrocardiography (ECG) $(6,7)$. Development of torsades de pointes, which
Corresponding Author: Ibrahim Etem Dural

E-mail:

iedural@hotmail.com

Received: September 09, 2020 Accepted: December 04, 2020 Published: December 31, 2020

\section{Suggested citation:}

Dural El, Nadir Y. Adverse Cardiac Events Among the Patients Using Hydroxychloroquine and Azithromycin in COVID-19. Infect Dis Clin Microbiol 2020; 3 : 158-162.

DOI: $10.36519 / \mathrm{idcm} .2020 .0023$ 
is a form of polymorphic ventricular tachycardia, is the most undesirable situation in QTc prolongation.

Adverse cardiac events related to the use of HQN was reported $(8,9)$. We aimed to describe the adverse cardiac events associated with using both HQNhqn and azithromycinAZ for COVID-19.

\section{MATERIALS AND METHODS}

We included 93 hospitalized COVID-19 patients who had positive polymerase chain reaction (PCR) test results or clinical and radiological findings. The patients who had QTc interval over 460 msec were excluded. The HQNhqn dose was $200 \mathrm{mg}$ twice a day for five days with or without concomitant AZ $500 \mathrm{mg}$ once a day. On the first day and fifth day of hospitalization, ECG findings of the patients were reviewed. In ECG records, PR interval, QRS duration, QT interval, QTc interval, and JTc interval were calculated. Bazett's formula was used when calculating the QTc interval. The JTc interval was obtained by subtracting QRS duration from the QTc interval. The ECG values of the first day and fifth day were compared. QTC prolongation $>40 \mathrm{msec}$ or exceeding $470 \mathrm{msec}$ was considered moderate, and prolongation > 60 msec or exceeding 500 msec erewas considered critical prolongation. In patients with QRS duration >120 msec, JTc duration was considered. JTc prolongation $>60$ msec or exceeding 410 msec were considered as critical prolongation.

\section{Statistical Analysis}

Continuous variables were presented by mean and standard deviation, whereas categorical variables by percentages. The paired t-test was used in comparison ofto compare paired mean values;valuses, otherwise, the Mann-Whitney U test was used. Categorical variables were compared with a chi-square and Fisher exact test. Statistical analysis was performed using IBM SPSS Statistics 22. Statistical significance was set as $\mathrm{p}<0.05$.

\section{RESULTS}

Among 93 patients, 40 (43\%) patients received HQN monotherapy 53 (57\%) patients received HQN and azithromycinAZ therapy. The mean age of the patients in HQN+AZ group was older than HQN

\section{HIGHLIGHTS}

Numerous publications are published on the safety of hydroxychloroquine and azithromycin therapy used in the treatment of COVID-19. In this study, the cardiac side effect rates of these two drugs were found to be compatible with the literature and routine clinical practise.

group (Table 1). The proportion of comorbidities among HQN+AZ group was significantly higher than HQN group (Table 1). The PCR test positivity, being in intensive care, elevated $C$ reactive protein (CRP) and prolongation ofprolonged hospital stay were higher in HQN + AZ group (Table 1).

When the first day and fifth day ECG records are compared, no significant difference was found in terms of PR intervals ( $p=0.872)$ and $Q R S$ duration ( $p=465)$, however in the fifth day, QTc intervals were found to be significantly prolonged in $\mathrm{HQN}+\mathrm{AZ}$ group ( $12.6+21)$ than the HQN group $(6.5 \pm 16.1 \mathrm{~ms})$, $(p=0.05$, Table 1$)$.

The finding of ECG werewas detailed in Table 2. The QTC interval exceeded $470 \mathrm{msec}$ in four patients, and in two patients, the QTC was prolonged $>40$ msec. Moderate prolongation was detected in six patients (6.45\%). QTc interval exceeded $500 \mathrm{msec}$ in three patients and all of them were female in the combination therapy group. In two of these three patients, the QTc prolonged > $60 \mathrm{msec}$. The QRSother patient's QRS duration was calculated as 144 msec on the first ECG and $142 \mathrm{msec}$ on the second ECG. Therefore, JTc interval was evaluated on this patient. The first JTc interval was $346 \mathrm{~ms}$, and the second JTc distance was $364 \mathrm{~ms}$. This patient was not evaluated as critical QTC prolongation. Critical QTc prolongation was detected in two patients (2.15). Also, in the combination therapy group, this ratio was 3.7. One of the patients was admitted with acute atrial fibrillation and a beta-blocker was started, and then a sinus rhythm was provided by cardioversion.

In total, 13 patients received favipiravir treatment. One of them received both convalescent plasma and tocilizumab; one patient received only con- 
Table 1. Baseline of clinical characteristics of patients

\begin{tabular}{|c|c|c|c|c|}
\hline Characteristics & Total (n:93) & $\begin{array}{l}\text { Only hydroxychloroquine } \\
\text { (n:40) }\end{array}$ & $\begin{array}{l}\text { Hydroxychloroquine and } \\
\text { azithromycin (n:53) }\end{array}$ & $P$ value \\
\hline Age & $50.6( \pm 18.8)$ & $36.4( \pm 13.8)$ & $61.4( \pm 15.1)$ & $<.001$ \\
\hline Female & $48(51.6 \%)$ & $16(40 \%)$ & $32(60.3 \%)$ & .08 \\
\hline \multicolumn{5}{|l|}{ Chronic disease } \\
\hline $\mathrm{HT}$ & $16(17.2 \%)$ & $1(2.5 \%)$ & $15(28.3 \%)$ & .002 \\
\hline DM & $8(8.6 \%)$ & $1(2.5 \%)$ & $7(13.2 \%)$ & .14 \\
\hline $\mathrm{HF}$ & $6(6.5 \%)$ & 0 & $6(11.3 \%)$ & .03 \\
\hline CAD & $6(6.5 \%)$ & 0 & $6(11.3 \%)$ & .03 \\
\hline $\mathrm{AF}$ & $2(2.2 \%)$ & 0 & $2(3.8 \%)$ & .504 \\
\hline COPD & $1(0.7)$ & $10(58.8)$ & $11(7.0)$ & $<0.001$ \\
\hline Length of stay & $10( \pm 8.5)$ & $9.6( \pm 7.6)$ & $10.4( \pm 9.1)$ & .02 \\
\hline PCR test $(+)$ & $41(\% 44.1)$ & $14(35 \%)$ & $27(50.9 \%)$ & .007 \\
\hline Death & $3(3.2 \%)$ & 0 & $3(3.2 \%)$ & .25 \\
\hline Intensif care & $8(8.6 \%)$ & 0 & $8(15.1 \%)$ & .009 \\
\hline \multicolumn{5}{|l|}{ Laboratory } \\
\hline Creatinin & $0.9( \pm 0.4)$ & $0.87( \pm 0.18)$ & $1( \pm 0.5)$ & .432 \\
\hline WBC & $6643( \pm 2892)$ & $6590( \pm 2052)$ & $6674( \pm 3294)$ & .58 \\
\hline CRP & $26.8( \pm 40)$ & $13.3( \pm 18.9)$ & $34.7( \pm 47.2)$ & .003 \\
\hline \multicolumn{5}{|c|}{ ECG measurements } \\
\hline $\mathrm{PR}_{1}$ & $148.6( \pm 19.9)$ & $149.2( \pm 21.5)$ & $148.1( \pm 18.8)$ & .988 \\
\hline $\mathrm{PR}_{2}$ & $148.1( \pm 18.5)$ & $147.9( \pm 19.3)$ & $148.2( \pm 18.2)$ & .813 \\
\hline $\mathrm{QRS}_{1}$ & $90.7( \pm 11.9)$ & $89.4( \pm 10.4)$ & $91.8( \pm 21.6)$ & .596 \\
\hline $\mathrm{QRS}_{2}$ & $90.9( \pm 12)$ & $90( \pm 9.9)$ & $91.7( \pm 13.4)$ & .758 \\
\hline $\mathrm{QTC}_{1}$ & $415( \pm 26.6)$ & $407.9( \pm 25.5)$ & $420.4( \pm 26.4)$ & .03 \\
\hline $\mathrm{QTC}_{2}$ & $425.1( \pm 29.3)$ & $414.5( \pm 23.6)$ & $433.1( \pm 66.3)$ & .005 \\
\hline$\Delta \mathrm{QTC}\left(\mathrm{QTC} \mathrm{C}_{2}-\mathrm{QTC} \mathrm{C}_{1}\right)$ & $10( \pm 19.2)$ & $6.5( \pm 16.1)$ & $12.6( \pm 21)$ & .338 \\
\hline
\end{tabular}

HT: Hypertension, DM: Diabetes mellitus, HF: Heart failure, AF: Atrial fibrillation, COPD: Chronic obstructive pulmonary disease, PCR: polymerase chain reaction, WBC: White blood cell, CRP: C reactive protein, ECG: electrocardiography, PR1, QRS1, QTc1: First day measurement, PR2, QRS2, QTc2: Fifth day measurement 
Table 2. Electrocardiographical measurements

\begin{tabular}{|c|c|c|c|}
\hline Patients & PR1 & PR2 & $P$ value \\
\hline Total & $148.6( \pm 19.9)$ & $148.1( \pm 18.5)$ & .872 \\
\hline Only hydroxychloroquine (n:40) & $149.2( \pm 21.5)$ & $147.9( \pm 19.3)$ & .214 \\
\hline \multirow[t]{2}{*}{ Hydroxychloroquine and azithromycin (n:53) } & $148.1( \pm 18.8)$ & $148.2( \pm 18.2)$ & .711 \\
\hline & QRS1 & QRS2 & \\
\hline Total & $90.7( \pm 11.9)$ & $90.9( \pm 12)$ & .465 \\
\hline Only hydroxychloroquine ( $\mathrm{n}: 40)$ & $89.4( \pm 10.4)$ & $90( \pm 9.9)$ & .280 \\
\hline \multirow[t]{2}{*}{ Hydroxychloroquine and azithromycin (n:53) } & $91.8( \pm 21.6)$ & $91.7( \pm 13.4)$ & 1 \\
\hline & QTC1 & QTC2 & \\
\hline Total & $415( \pm 26.6)$ & $425.1( \pm 29.3)$ & $<.001$ \\
\hline Only hydroxychloroquine (n:40) & $407.9( \pm 25.5)$ & $414.5( \pm 23.6)$ & .015 \\
\hline Hydroxychloroquine and azithromycin (n:53) & $420.4( \pm 26.4)$ & $433.1( \pm 66.3)$ & $<.001$ \\
\hline
\end{tabular}

PR1, QRS1, QTc1: First day measurement, PR2, QRS2, QTc2: Fifth day measurement

valescent plasma, the other one only tocilizumab. None of these patients had prolonged QTC.

In total, three patients died (3.22\%). The cause of death was reported as acute respiratory distress syndrome and no cardiac complications, including QTc prolongation, were detected in these patients.

\section{DISCUSSION}

Since there was no specific drug for treatment, a variety of drugs were used in COVID-19 infection. Turkish Ministry of Health suggested HQN or $\mathrm{HQN}+\mathrm{AZ}$. Despite the frequent use of HQN for autoimmune diseases, reported cardiac side effects were limited in the literatüreiterature (10). However, it is known that it has effects on the conduction system by blocking potassium ion channels in the heart. Although side effects such as PR interval prolongation, QRS duration widening and atrioventricular block are also observed, QTc prolongation seems to be a more serious side effect recently (11). While this side effect was known to be rare by using for more than one year or acutely with eroverdose, recently the rate of side effects was reported up to $21 \%$ in using short-term and therapeutic dose $(9$, 11,12). In our study, no detection of QTc prolongation with HQN dose, was400 mg daily (total 2 gr), seems to be more compatible with literature and clinical practice.

AZ is a macrolide group antibiotic that is still used in respiratory and urinary tract infections (5). It is known that the drug affects multi-ion channels and causes heart conduction problems, especially QTc prolongation. Therefore, it is avoided to be used in elder ages, especially $>60$ years of age, because of the increased ratio of this side effect (13). Two drugs were previously used for three days in malaria treatment, and QTC prolongation was detected with no critical side effects.

Almost all the hospitalized patients in Turkey received treatment for at least five days, and this period was extended to 10 days as a result of clinical evaluations. At the end of the fifth day, we found critical QT prolongation in two (3.7\%) patients receiving HQN and AZ combined therapy. One of the patients was on antiarrhythmic therapy, and the other one was 82 years old.

In HQN monotherapy treatmentHQN for five days, QTC prolongation was observed while no PR interval prolongation, no QRS widening was observed. However, the QTC prolongation did not reach the critical level after five days of treatment. Critical 
QTc prolongation in patients receiving dual therapy was observed in two of 53 patients. ECG monitorization can be more frequent in patients taking HQN and AZ together. Especially in patients with dysrhythmia, received antiarrhythmic therapy, with organic heart disease and $>80$ years old, daily ECG monitorization seems to be appropriate.
In conclusion, close ECG monitoring is necessary, and the frequency of ECG monitorization should be individualized in patients receiving azithromycin with hydroxychloroquine.
Informed Consent: Written consent was obtained from the patient.

Peer-review: Externally peer-reviewed

Author Contributions: Concept - İ.E.D.; Design - İ.E.D.; Supervision - Y.N.; Fundings - İ.E.D., Y.N.; Materials - Y.N.; Data Collection and/ or Processing - İ.E.D., Y.N.; Analysis and/or Interpretation - Y.N.;
Literature Review - İ.E.D.; Writer - İ.E.D.; Critical Reviews - Y.N.

Conflict of Interest: The authors have no conflict of interest to declare.

Financial Disclosure: The authors declared that this study has received no financial support.

\section{REFERENCES}

1 DemirbilekY, Pehlivantürk G, Özgüler ZÖ, Alp Meşe E. COVID-19 outbreak control, example of ministry of health of Turkey. Turk J Med Sci 2020; 50: 489-94.

2 Shi Y, Wang G, Cai XP, Deng JW, Zheng L, Zhu HH, et al. An overview of COVID-19. J Zhejiang Univ Sci B 2020; 21: 343-60.

3 Gautret P, Lagier JC, Parola P, Hoang VT, Meddeb L, Sevestre $\mathrm{J}$, et al. Clinical and microbiological effect of a combination of hydroxychloroquine and azithromycin in 80 COVID-19 patients with at least a six-day follow up: A pilot observational study. Travel Med Infect Dis 2020; 34: 101663.

4 Ponticelli C, Moroni G. Hydroxychloroquine in systemic lupus erythematosus (SLE). Expert Opin Drug Saf 2017; 16: 411-19.

5 Bakheit AH, Al-Hadiya BM, Abd-Elgalil AA. Azithromycin. Profiles Drug Subst Excip Relat Methodol 2014; 39: 1-40.

6 Chen CY, Wang FL, Lin CC. Chronic hydroxychloroquine use associated with QT prolongation and refractory ventricular arrhythmia. Clin Toxicol 2006; 44: 173-5

7 Choi Y, Lim HS, Chung D, Choi JG, Yoon D. Risk evaluation of azithromycin-induced QT prolongation in real-world practice. Biomed Res Int 2018; 2018: 1574806.

8 Zengin R, Sarıkaya ZT, Karadağ N, Çuhadaroğlu Ç, Ergönül Ö, Kocagöz S. Adverse Cardiac Events Related to Hydroxychloro- quine Prophylaxis and Treatment of COVID-19. Infect Dis Clin Microbiol 2020; 1: 24-26.

9 Çelik HG, Keske Ş, Şener Ü, Tekbaş M, Kapmaz M, Şahin ŞT, et al. Why we should be more careful using hydroxychloroquine in influenza season during COVID-19 pandemic? Int J Infect Dis. 2020 Oct 29;102:389-391. doi: 10.1016/j.ijid.2020.10.080.

10 Ben-Zvi I, Kivity S, Langevitz P, Shoenfeld Y. Hydroxychloroquine: from malaria to autoimmunity. Clin Rev Allergy Immunol 2012; 42: 145-53.

11 Chatre C, Roubille F, Vernhet H, Jorgensen C, Pers YM. Cardiac complications attributed to chloroquine and hydroxychloroquine: a systematic review of the literature. Drug Saf 2018; 41: 919-31.

12 Mercuro NJ, Yen CF, Shim DJ, Maher TR, McCoy CM, Zimetbaum PJ, et al. Risk of QT interval prolongation associated with use of hydroxychloroquine with or without concomitant azithromycin among hospitalized patients testing positive for coronavirus disease 2019 (COVID-19). JAMA Cardiol 2020: 5: 1036-41.

13 Yang Z, Prinsen JK, Bersell KR, Shen W, Yermalitskaya L, Sidorova T, et al. Azithromycin causes a novel proarrhythmic syndrome. Circ Arrhythm Electrophysiol 2017; 10: e003560. 